COVER STORY

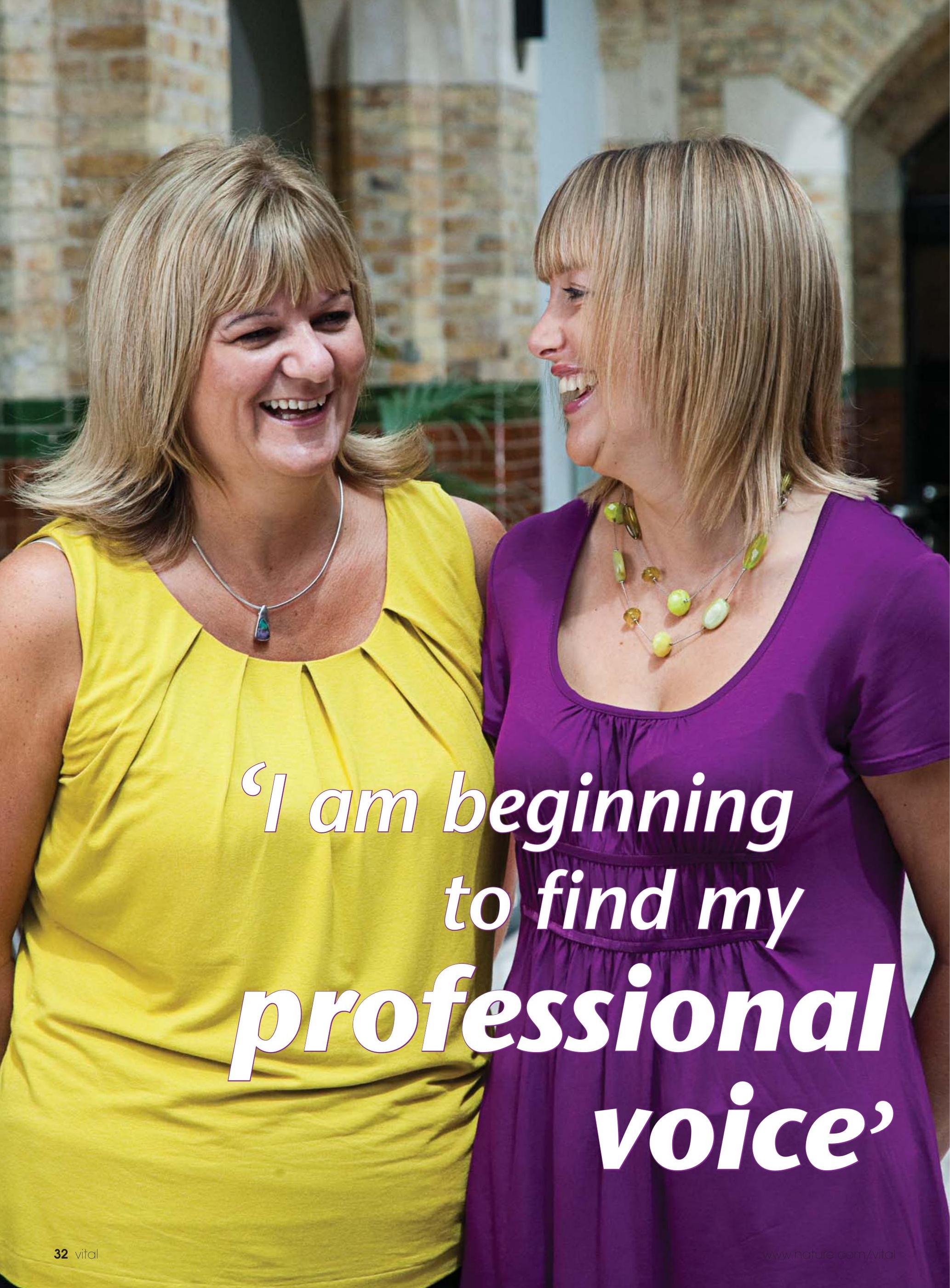




\section{Meet Sue and}

Nicky, some of the

\section{first students on the}

\section{exciting new degree} designed exclusively for ambitious dental care professionals - the BSc in Primary Dental Care at the University of Kent.

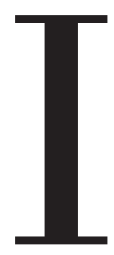

n September 2008 the first group of dental care professionals (DCPs) began studying the BSc in Primary Dental Care at the University of Kent's Division of Dentistry, Medway Campus. The degree is aimed exclusively at professionally qualified DCPs already registered with the GDC and employed within a primary dental care setting. When the course was launched, lecturer Debbie Reed explained that it will 'equip dental care workers for longer and more rewarding careers through a mix of greater professional and academic development.'

The course curriculum includes:

- Critical appraisal of literature

- Audit

- Mentorship

- Communication and professional voice

- Law and ethics

- Oral health education

- Diet and nutrition

- Practice appraisal and change management

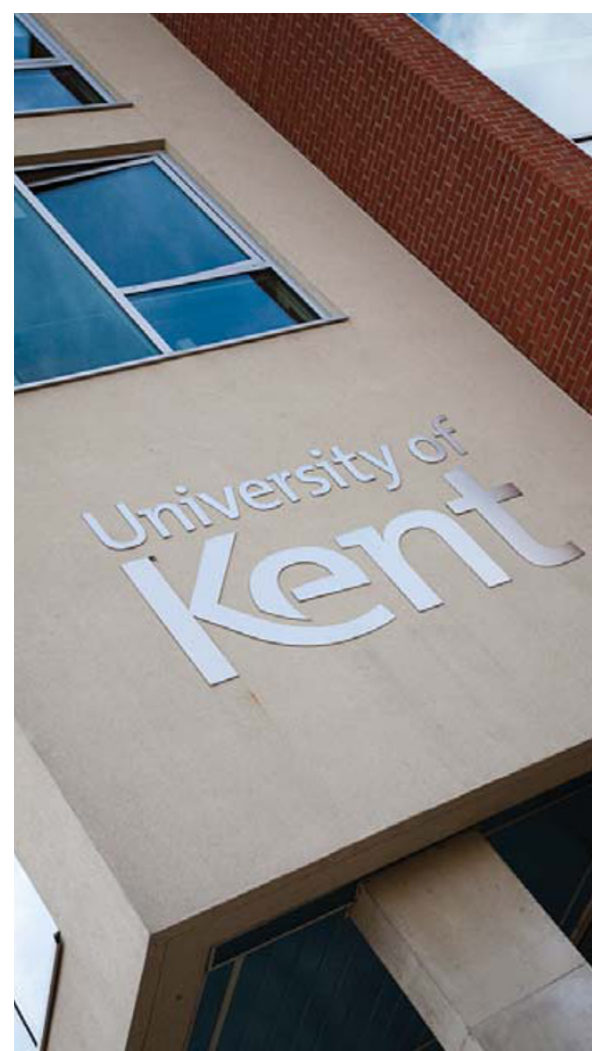

- Research skills

- Teamwork and leadership.

Nicky Gough and Sue Bagnall have recently completed the first year of the course, which can be studied in three years full-time or six years part-time (students who successfully complete Stage One and Stage Two and who decide to leave the programme will be eligible for a diploma). They told Vital how they are getting on and their impressions of the course and campus.

\section{What attracted you to the BSc in Primary Dental Care?}

Nicky: The prospect of attaining a degree in a subject I enjoy. I thought that it would enable me to become a more enthusiastic, confident and ethical DCP, and improve standards of care for my patients. I was also attracted by the flexibility of the course, with some private study, study on the job and some residential taught weekends. The prospect of meeting new people from a range of dental backgrounds also appealed.

Sue: I had been visiting universities with my son and was extremely excited for him at the prospect of beginning his studies. I was elated by the standard of facilities available at the different universities and began to ponder the idea of furthering my own education to degree level. I attended the open day for the BSc in Primary Dental Care at Kent University with my husband and was immediately drawn to the programme of study and its flexibility.

\section{How did you find the first year of the course?}

Sue: It has been a challenging but enlightening experience. I have had to learn to plan and prioritise my time to enable me to complete my research, written assignments and fulfil my commitment to my patients, colleagues and family. I've really enjoyed meeting the other students at the weekend sessions and the lecturers are very dynamic professionals with so much knowledge to share with us.

Even though I live a four-hour drive away from the campus, I really feel part of the university. I have access to all the facilities and look forward to the lecture weekends. As a group we've formed a really close bond and there's lots of lively debate from likeminded DCPs.

Nicky: It's an excellent course and I really enjoy the modular system of learning. The induction week at the start of the course took into account the fact that many of us had been out of the education system for a while and covered such topics as essay writing, learning styles and time management.

\section{Sue Bagnall}

Background: When Sue left school she found employment as a trainee dental technician; within a year she decided she would enjoy working in the surgery with patients. She trained as a dental nurse at the Birmingham Dental Hospital and went on to work in general dental practice.

In 1989 Sue studied for the Certificate in Dental Health Education and spent some time delivering dental health education locally. In 1995 she began training to become a dental hygienist and has worked in general dental practice ever since. She read about the BSC in Primary Dental Care last year in Vital. ${ }^{1}$

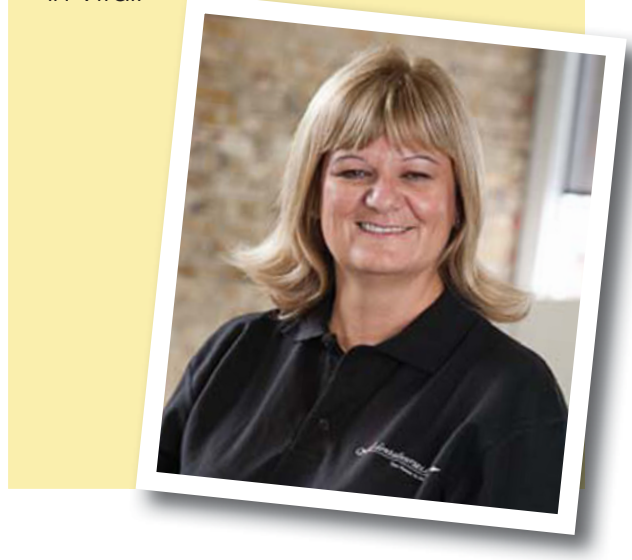

\section{Nicky Gough}

Background: After finishing her GCSEs, Nicky started working as a dental nurse in 1991 and completed the National Certificate in 1993. She started training to become a dental hygienist two years later on the final one year course and qualified in 1996.

Nicky has now been qualified for nearly 13 years and enjoys working in a variety of private and national health dental practices in the South of England. She has two children aged eight and ten and currently works part-time.

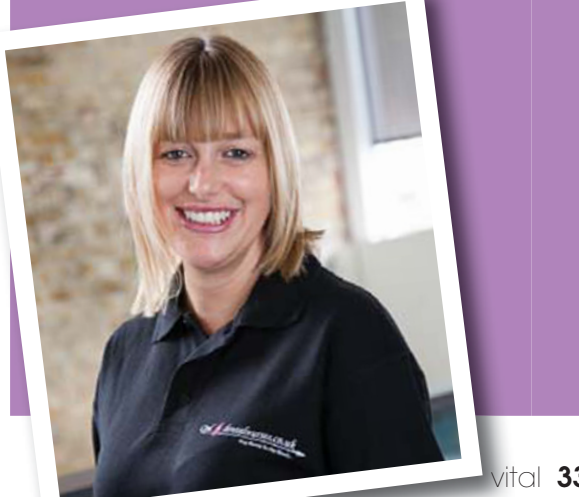


'Despite joining the Student

\section{Union, rather}

than go to toga

parties we have

been more

civilised and

had late night

debates over

cheese and wine!'

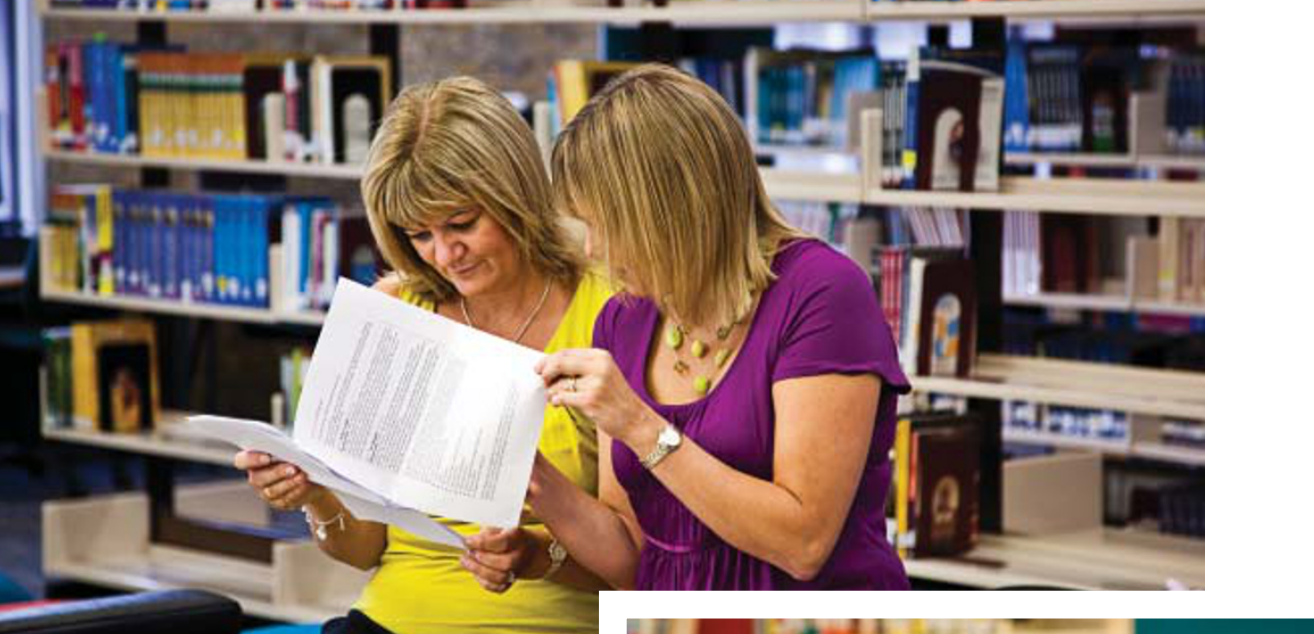

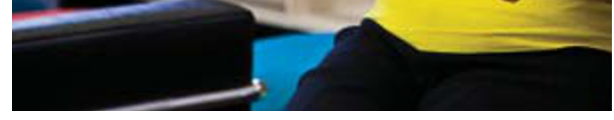

On the residential weekends we all enjoy an evening out together after we've been given the results and feedback from the previous module. This gives us the opportunity to support each other which is a real boost for the next module. I have enjoyed being able to pass on my new knowledge to colleagues at work and also feel I have improved my communication skills with my patients.

The first year has passed so quickly and it's amazing to think that in just two years our group will be the first graduates on this course!

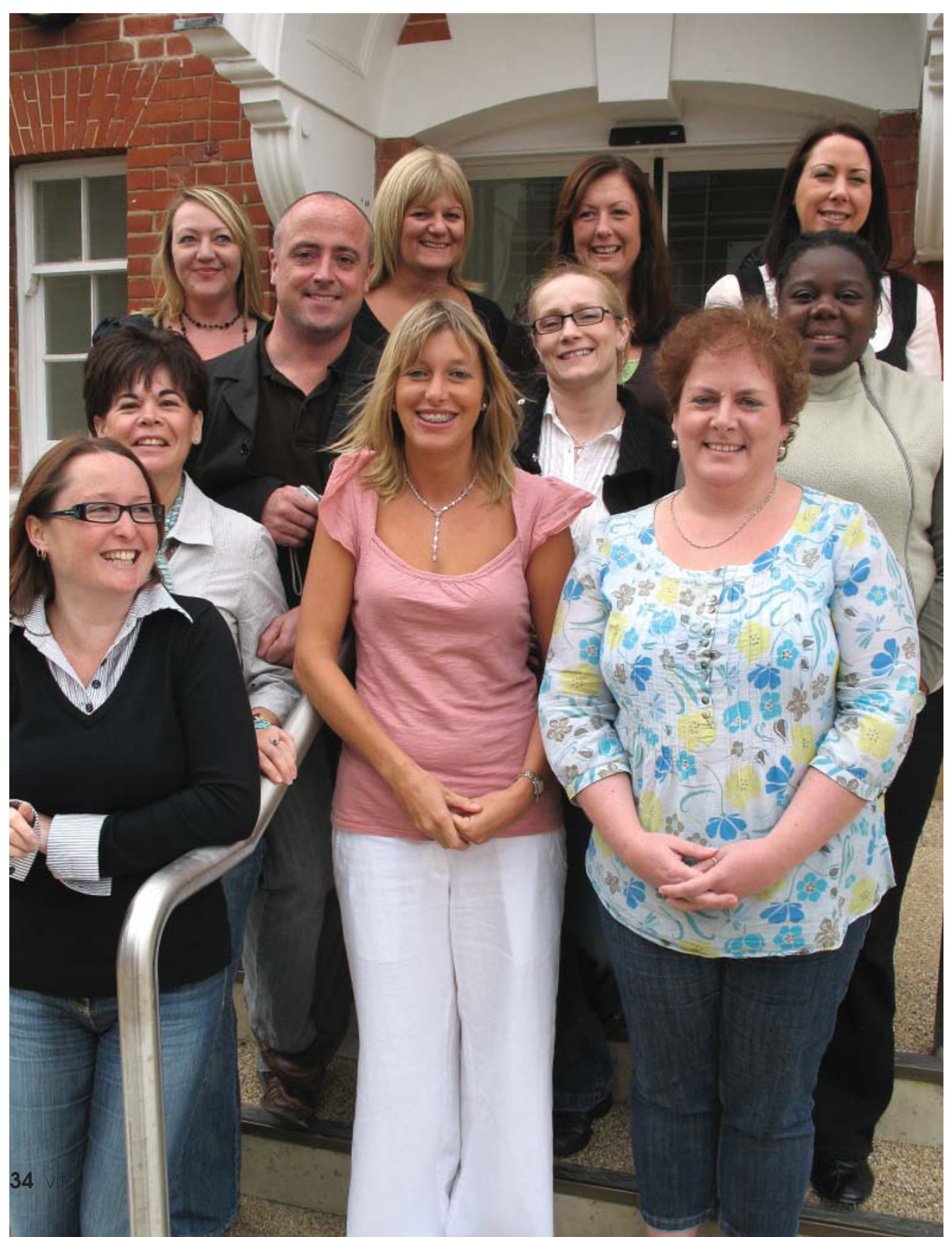

What are the facilities like on campus? Sue: The Medway Campus is right next to Chatham's Historic Dockyard and is a wonderful location. The classrooms are large, light and modern; there's a selection of cafes to choose from and on the weekend sessions we have spent a lot of time in the Drill Hall library working on presentations together. There's plenty of support by way of tutorials and the Kent University Learning Advisory Service. We also have email addresses for the external lecturers, who are happy to be contacted should we need any help.

Nicky: The IT facilities are so different to how I remember them from school and this course has really improved my IT skills through use of the interactive blackboard learning system. The library is open until midnight on the residential weekends and our group have been known to be in there close to closing time! We can borrow books and access journals electronically which makes researching information for written assignments so much easier.

Despite joining the Student Union, rather than go to toga parties we have been more civilised and had late night debates over cheese and wine!

How do you handle the balance between work and study?

Nicky: I am lucky to have received the full support of my family, friends and colleagues 


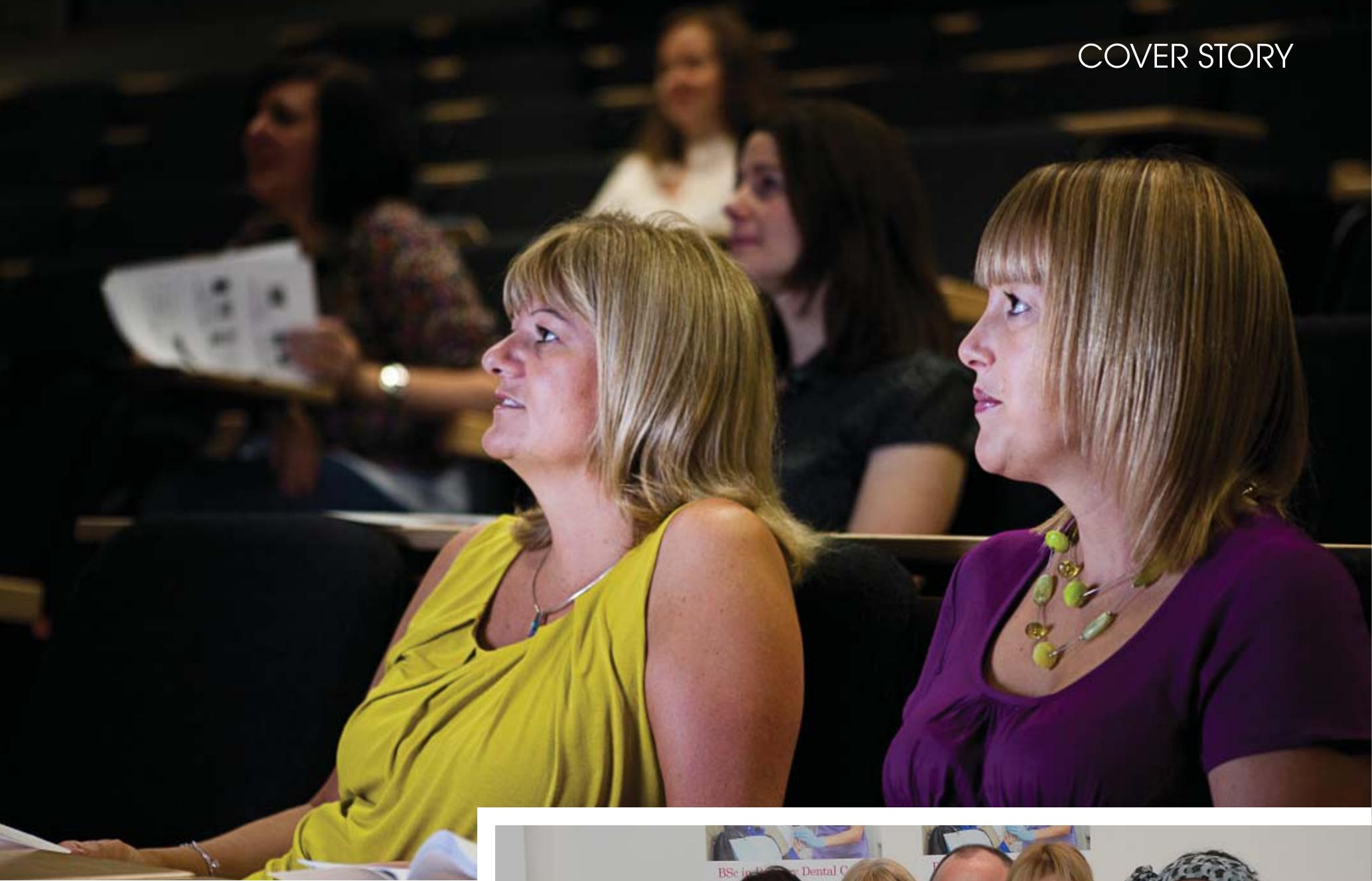

but handling the balance has been the most challenging aspect for me. Speaking to other students I realise that we all have different ways of working; I work best early in the mornings. Some of the work can be completed during lunch hours or at the end of the day. Sue: I try to allocate time each day to study; sometimes it's early in the mornings before my working day starts, sometimes during lunch and sometimes in the evenings. It is necessary to use up most of my weekends completing the module assignments and this is my choice. It is a flexible degree so if I wanted I could complete it over more years to lessen the workload. My husband is also a dental hygienist and he has been very supportive.

How has the degree benefited your professional working practice?

Sue: I now have a clearer understanding of the nationally set standards for dental care and have been able to share this with my colleagues. Developing my personal development portfolio (PDP) has provided me with a framework to organise my goals. I can now carefully choose which CPD activities I undertake and introduce the new skills into my daily practice.

Nicky: The course has already made me a more motivated, confident, reflective and competent practitioner. Through the process of reflection I have taken steps to improve my clinical and professional practice. By

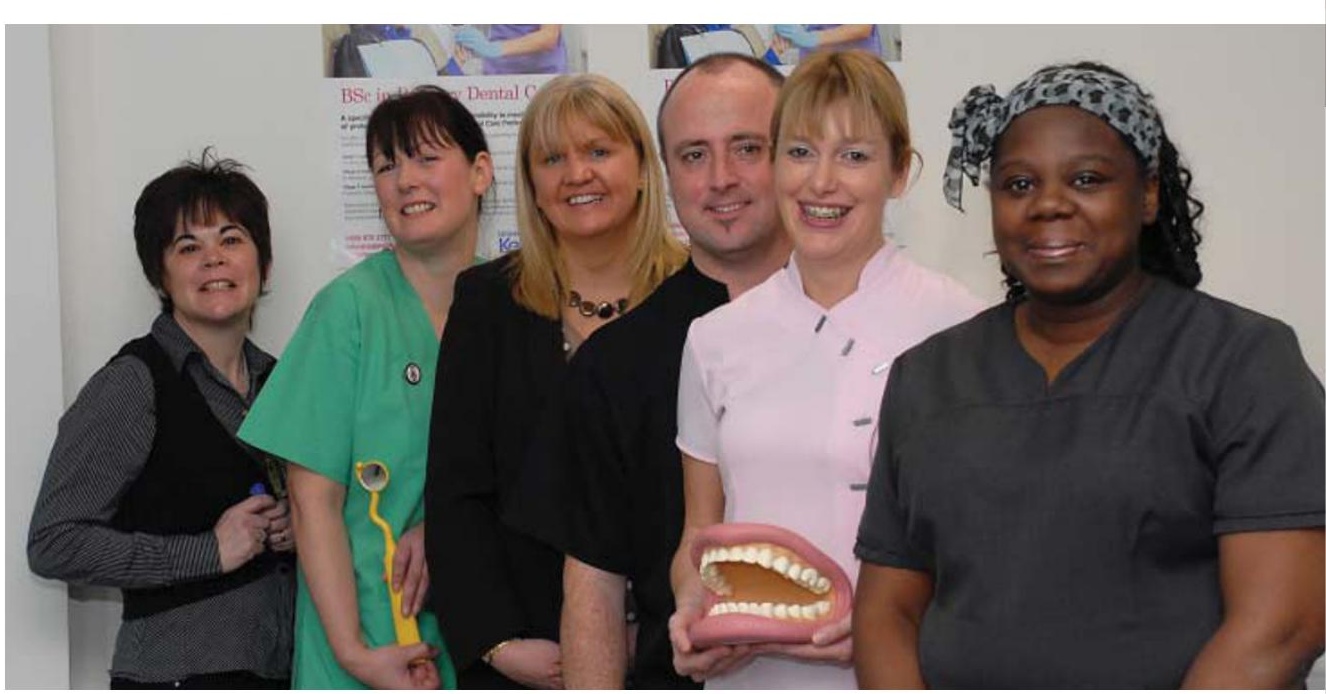

\section{'T can now}

\section{carefully}

choose which

\section{CPD activities}

\section{I undertake}

\section{and introduce}

\section{the new skills}

into my daily

practice.' working through the reflective cycle, I feel that I am beginning to find my professional voice.

I have discussed the knowledge I gained from the core skills module in areas such as audit, clinical governance and key skills with my colleagues and as a result the standard of care within the practice has improved. All members of the team have contributed to this which has raised staff morale.

What are you planning when you complete your degree?

Nicky and Sue have been firm friends since studying dental hygiene together and sharing accommodation at King's Dental School in London. Since starting the BSc in Primary Dental Care they have plans to share their knowledge with dental nurses by launching a CPD website. 
Nicky: Our new business cpd4dentalnurses. co.uk will provide dental nurses with access to all their verifiable and non-verifiable CPD needs and provide opportunities for dental nurses to share ideas on the forum and socialise in the chat room.

Sue: We are aware that many nurses, particularly in rural locations, may have difficulty accessing CPD and we want to share our enthusiasm for dentistry with them.

Do you have any advice for others thinking of doing the BSc?

Nicky: The BSc course at Kent is excellent for dedicated DCPs who are wishing to extend their knowledge and improve the standard of care they give their patients. As a student you should be prepared for the roller coaster of emotions that comes with studying for a

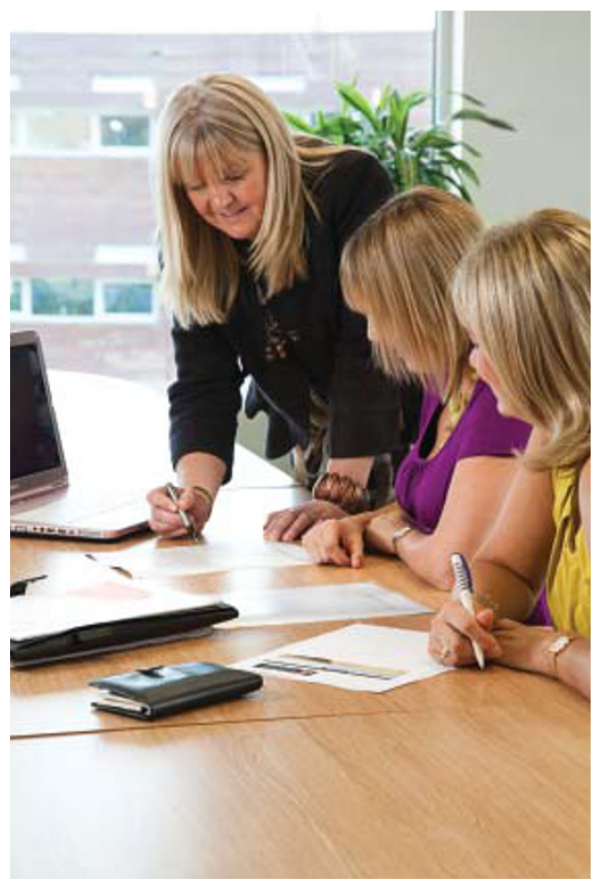

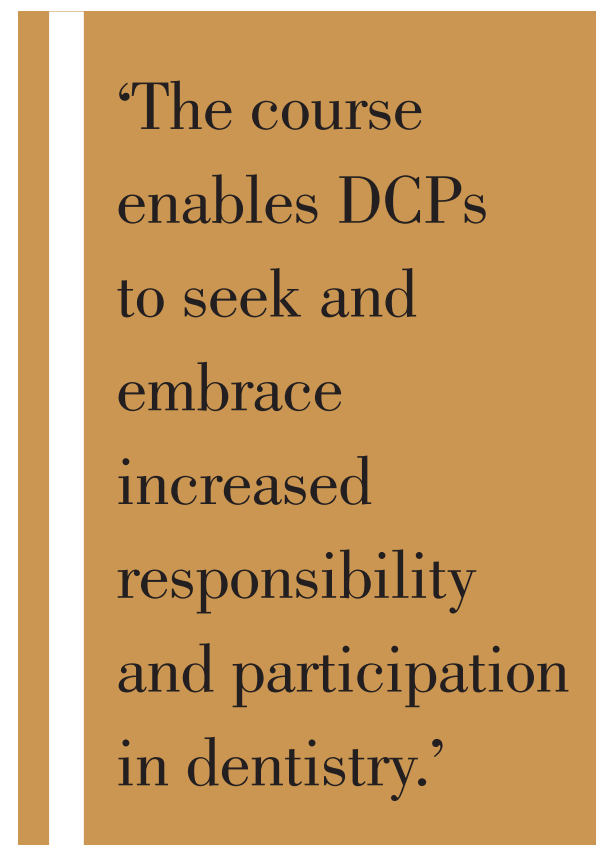

degree while juggling work. However, you will also meet some really interesting people, make new friends and enjoy being part of a university life while studying for a degree in our rapidly evolving profession.

Sue: The course enables DCPs to seek and embrace increased responsibility and participation in dentistry. It does demand a high level of commitment to personal study but

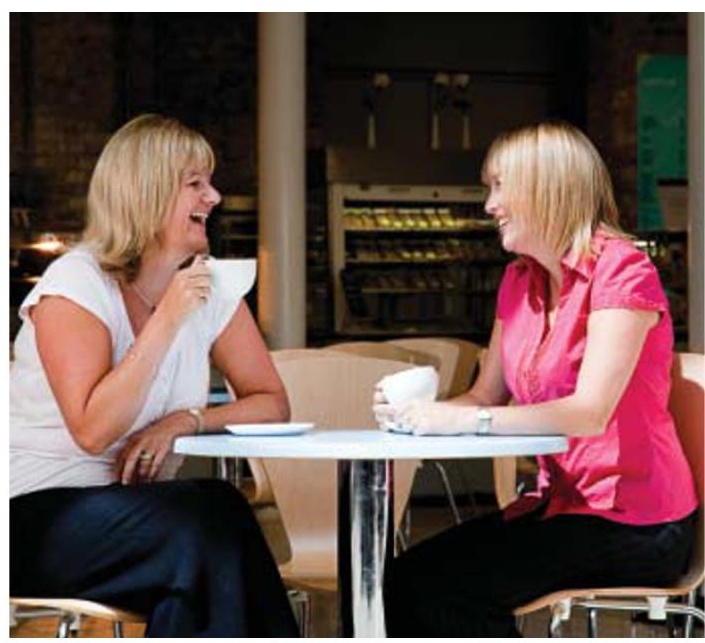

as our course director, Debbie Reed, reminds us, 'nobody said it was going to be easy'. I have reached the end of the first year with no regrets at undertaking a university degree whilst working, making sure our son is happy and safe at his university and starting our new business, cpd4dentalnurses.co.uk.

www.cpd4dentalnurses.co.uk launched in August.

For more information on the BSc in Primary DentalCare,emailinformation@kent.ac.ukor telephone 08009753777.

1. DCP degree launched. Vital autumn 2008; 9.

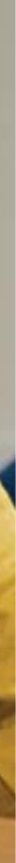

